structure. Increased $\mathrm{AT}_{1}$ receptor $\mathrm{mRNA}$ and protein. Decreased $\mathrm{AT}_{2}$ receptor mRNA and protein express. valsartan improved left ventricular function $\left(+\mathrm{dp} / \mathrm{dt}_{\max } 1337 \pm 226 \mathrm{~mm} \mathrm{Hg.s}{ }^{-1} ;-\mathrm{dp} / \mathrm{dt}_{\max }\right.$ $-871 \pm 208 \mathrm{~mm} \mathrm{Hg} . \mathrm{s}^{-1}$, compared with I/R group, all $\left.\mathrm{p}<0.01\right)$, increased coronary effluent $\left(4.2 \pm \Delta 0.7 \mathrm{ml} . \mathrm{min}^{-1}\right.$, compared with I/R group, $\mathrm{p}<0.01)$. Increased $\mathrm{AT}_{2}$ receptor $\mathrm{mRNA}$ and protein express with no changes in $\mathrm{AT}_{1}$ receptor mRNA and protein express.

Conclusions $\mathrm{AT}_{1}$ receptor blockade valsartan induces short-term cardioprotection associated with enhanced $\mathrm{AT}_{2}$ receptor expression during myocardial ischaemia reperfusion.

\section{e0349 CLINICAL OBSERVATION ON DIFFERENT DOSAGE OF VALSARTAN IN TREATMENT OF HEART FAILURE}

doi:10.1136/hrt.2010.208967.349

Sun Yueling, Chen Su, Tu Yuanchao. Xinhua Hospital of Hubei Province

Objective To explore the clinical value of different dosage of valsartan in treatment of chronic heartfailure (CHF).

Methods 99 patient $\mathrm{s}$ with CHF were randomly divided into three groups: benazepril group (group A, $10 \mathrm{mg} / \mathrm{d}$ ), conventional dose valsartan group (group B, $80 \mathrm{mg} / \mathrm{d}$ ) and high dose valsartan group (groups C, $80 \mathrm{mg} / \mathrm{d}, 2$ times per day). Levels of Angiotensin II (Ang II), aldosterone (ALD) and brain nat riuretic peptide (BNP) were detected, and the changes of left ventricular ejection fraction (LVEF) were measured before and 6 months after treatment.

Results BNP, ALD, Ang II were decreased significantly in 3 groups $(p<0.05)$, while LVEF increased significantly $(p<0.05)$ after the treatment. Compared with those of group A and B, BNP and ALD were significantly decreased while LVEF was significantly increased after treatment in group $C(p<0.05)$. ALD in group B decreased significantly compared with that of group A $(p<0.05)$, while the other indexes were not significantly changed.

Conclusions Valsartan, similar to benazepril, reverses ventricular remodelling and improves cardiac function, high dose valsartan reverses ventricular remodelling and improves cardiac function more effectively than benazepril and conventional dose valsartan.

\section{e0350 EFFECTS OF PROBUCOL ON ANTI-OXIDISING AND ANTI- INFLAMIMATION IN PATIENTS WITH ACUTE CORONARY SYNDROME}

doi:10.1136/hrt.2010.208967.350

Yan Kaili, Liu Hanhua, Sun Yueling, Chen Su, Tu Yuanchao. Xinhua Hospital of Hubei Province

Objective To observe the effects of probucol on blood levels of oxidative low density lipoprotein antibody (oxLDL-Ab), highsensitive C-reactive protein (hs-CRP) and interleukin-18 (IL-18) in patients with acute coronary syndrome (ACS).

Methods 81 patients with ACS were divided randomly into a Probucol treatment group ( $\mathrm{p}$ group, $\mathrm{n}=41$ ) and a routine treatment group ( $\mathrm{R}$ group, $\mathrm{n}=40$ ). OxLDL-Ab, hs-CRP and IL-18 were respectively measured in peripheral blood before therapy. The level of OxLDL-Ab was measured again after a 4-week treatment. The levels of hs-CRP and IL-18 were measured again after 1-week treatment. The frequency of typical angina of $p$ group and $R$ group in the last week of treatment was analysed.

Results The levels of oxLDL-Ab, hs-CRP and IL-18 were obviously lower in $\mathrm{p}$ group compared with $\mathrm{R}$ group after treatment $(p<0.05)$. The frequency of typical angina of $p$ group in the last week of treatment was obviously lower than that of $\mathrm{R}$ group, and this was closely correlated with the decreased oxLDL-Ab values $(\mathrm{p}<0.05)$.
Conclusion Probucol had anti-oxidant and anti-inflammatory action in patients with ACS.

\section{e0351 RELATIONSHIP BETWEEN BRACHIUM-ANKLE PULSE WAVE VELOCITY AND 24HABPM, CONVENTIONAL BLOOD PRESSURE AND 24H ABPM IN PREHYPERTENSIVE SUBJECTS}

doi:10.1136/hrt.2010.208967.351

Zhao Yingxin, Lu Fanghong, Liu Zhendong, Wang Shujian, Sun Shangwen. Shandong Academy of Medical Sciences

Objective To study the relationship between brachium-ankle pulse wave velocity and $24 \mathrm{hABPM}$, conventional blood pressure and $24 \mathrm{hABPM}$ in prehypertensive subjects.

Methods 210 subjects were enrolled with prehypertension. Conventional blood pressure, 24-h ABPM and baPWV were performed. The patients were divided into dipper and non-dipper according to the decrease rate of nighttime MBP.

Results 1) Conventional blood pressure was obviously higher than mean 24-h BP, mean daylight BP and mean nighttime BP $(p<0.05)$. Conventional SBP was correlated with mean daylight BP $(r=0.431$, $p=0.023)$, and with mean 24-h SBP $(r=0.282, p=0.037)$. Conventional DBP was related to mean daylight DBP $(r=0.241, p=0.0397)$, and related to $24-h$ blood pressure $(r=0317, p=0.018)$. 2) baPWV was positive related to 24-h SBP, daylight SBP and PP, daylight and nighttime SBP load. 3) Conventional SBP was significant associated with daylight SBP $(r=0.577, p=0.022)$ and 24-h SBP $(r=0.611$, $\mathrm{p}=0.019$ ), and conventional DBP was significant related to daylight $\operatorname{DBP}(r=0.582, p=0.184)$ and 24-h DBP $(r=0.693, p=0.007)$ in nondipper prehypertensive patients. 4) baPWV was significant positive correlated with 24-h SBP, DBP, PP, daylight SBP, PP, SBP load, and nighttime SBP, PP, SBP load.

Conclusion There is a more value of 24-h ABPM in non-dipper prehypertensive patients than dipper prehypertensive patients. baPWV was closely correlation with 24-h SBP, daylight SBP and PP, daylight and nighttime SBP load in two groups.

\section{e0352 EFFICACY AND SAFETY OF ALISKIREN IN CHINESE PATIENTS WITH MILD OR MODERATE ESSENTIAL HYPERTENSION}

doi:10.1136/hrt.2010.208967.352

${ }^{1}$ Sun Ningling, ${ }^{2}$ Zhu Junren. ${ }^{1}$ People's Hospital Peking University; ${ }^{2}$ Zhongshan Hospital Shanghai

To assess the antihypertensive efficacy and safety of aliskiren compared with ramipril in Chinese patients with mild or moderate essential hypertension.

Methods This is a double-blind randomised, multicenter, parallel group, active-controlled study. Following washout and single-blind placebo run-in period, 1147 patients with essential hypertension (mean sitting diastolic blood pressure $[\mathrm{msDBP}] \geq 95$ and $110 \mathrm{~mm} \mathrm{Hg}$ ) were randomised to receive either aliskiren $300 \mathrm{mg}(\mathrm{n}=288), 150 \mathrm{mg}$ $(n=284), 75 \mathrm{mg}(\mathrm{n}=289)$ or ramipril $5 \mathrm{mg}(\mathrm{n}=286)$ for 8 weeks. Efficacy and safety were assessed at Week 2, 4 and 8 in treatment duration.

Results 994 (86.7\%) completed the study. At week 8, aliskiren therapy produced greater mean blood pressure reductions compared with ramipril therapy. All aliskiren dose groups were statistically non-inferior $(p<0.0001)$ to ramipril group in reducing msDBP. Aliskiren $300 \mathrm{mg}$ group also showed statistically significantly superior reductions in $\mathrm{msDBP}$ and $\mathrm{msSBP}$ compared to ramipril $5 \mathrm{mg}$ group ( $p=0.0002$ and $p=0.0073$, respectively). Blood pressure 